\title{
Parental satisfaction with the quality of care in a South African paediatric intensive care unit
}

\author{
C Mol, ${ }^{1}$ MB ChB; A C Argent ${ }^{2,3}$ FC Paed (SA), MD; B M Morrow, ${ }^{2}$ PhD, BSc (Physiotherapy) \\ ${ }^{1}$ Department of Paediatrics, Erasmus University, Rotterdam, Netherlands \\ ${ }^{2}$ Department of Paediatrics and Child Health, University of Cape Town, Cape Town, South Africa \\ ${ }^{3}$ Paediatric Intensive Care Unit, Red Cross War Memorial Children's Hospital, Cape Town, South Africa
}

Corresponding author: B Morrow (Brenda.Morrow@uct.ac.za)

\begin{abstract}
Background. The quality of family-centred care in the paediatric intensive care unit (PICU) has been poorly studied in South Africa (SA).
Objective. To explore parents' satisfaction with care in a PICU in SA.

Methods. A prospective descriptive survey study was conducted among a convenience sample of 100 parents of children admitted to the PICU for $\geq 48$ hours. Participants completed the EMpowerment of PArents in THe Intensive Care (EMPATHIC-30) questionnaire, which includes 30 closed questions rating satisfaction in different domains and four open-ended questions to qualitatively describe PICU experiences.

Results. Of the 100 admissions included in the study, 35\% were unplanned and $88 \%$ were mechanically ventilated. Parents were very satisfied with the quality of PICU care, with mean scores in all domains reaching $\geq 5.5$ on a 6-point Likert scale. Parents were most satisfied with the professional attitude of PICU staff, whereas the lowest scores were seen in the 'Information' and 'Parental participation' domains. The internal consistency (Cronbach's $\alpha$ ) associated with the different domains ranged between 0.25 (Parental participation) and 0.59 (Care and cure). The need for communication and support during the admission period, and the importance of environmental factors, proximity to the child, the attitude of medical staff and social support during the PICU stay emerged as common themes from the responses to the open-ended questions.

Conclusion. Although parents were generally well satisfied with the quality of care, improving family involvement and providing adequate information in the PICU can contribute to quality family-centred care.

Keywords. Family- centered care; patient- centered care; paediatric intensive care unit; quality of care
\end{abstract}

S Afr J Crit Care 2018;34(2):50-56. DOI:10.7196/SAJCC.201.v34i2.366

Over the past few decades, there have been major advances in paediatric intensive care, accompanied by improved survival rates. ${ }^{[1]}$ However, paediatric critical illness remains a major and stressful life event for the patients and their families, with potential long-term morbidity. ${ }^{[2]}$

Worldwide, the model of care for patients admitted to a paediatric intensive care unit (PICU) is changing towards a patient- and familycentred approach, defined by the American Academy of Pediatrics as an innovative approach to the planning, delivery, and evaluation of healthcare that is grounded in a mutually beneficial partnership among patients, families, and providers that recognises the importance of the family in the patient's life. ${ }^{\left[{ }^{[3]}\right.}$ Elsewhere patient- and family-centred care has been defined as care that is respectful of and responsive to individual patient (and family) preferences, needs and values, with an increasing recognition that involving family in the care of a critically ill patient can influence decision-making and clinical outcomes. ${ }^{[4]}$ Family-centred care requires that the patient's family participates and collaborates with healthcare professionals as partners in care. ${ }^{[5-9]}$ It has been suggested that the principles of family-centred care are more than simply 'family involvement in decision-making, and should incorporate how parents experience systems, the healthcare environment and facility design. ${ }^{[7]}$

Knowledge of parents' needs and their perceptions of care is necessary to improve quality of PICU care ${ }^{[5]}$ Exploring parental satisfaction related to the domains of family-centred care in the PICU is an important performance indicator of perceptions of PICU care. ${ }^{[10-13]}$ Latour et al. ${ }^{[10]}$ identified six domains in family-centred care, namely: respect; information and education; coordination of care; physical support; emotional support, and involvement of parents. Using these identified domains, Latour et al. ${ }^{[14,15]}$ subsequently developed and validated the full and abbreviated versions of the EMpowerment of PArents in THe Intensive Care (EMPATHIC) questionnaire, which evaluates parental satisfaction with the quality of care provided in a PICU.

Parents' experiences and level of satisfaction may differ between countries with varying sociocultural and -economic contexts. ${ }^{[16]}$ The EMPATHIC questionnaire has been used in countries such as Italy, Poland, Spain, Australia, France and Denmark to measure parent satisfaction, but not yet in poorly resourced countries. ${ }^{[13,17-20]}$ Although South Africa (SA) was reclassified as an upper middle-income country in 2011, there is substantial diversity in socioeconomic circumstances within the population. In 2011, 22.5\% of the SA population lived in informal housing, $26.6 \% \mathrm{did}$ not have a tap-water facility, $43.0 \%$ had no flushing toilets, and $16.3 \%$ had no electricity in their homes. ${ }^{[21]}$

The PICU at the Red Cross War Memorial Children's Hospital (RCWMCH) in Cape Town, SA, serves a diverse population, with most patients coming from extremely impoverished circumstances. Experiences of the PICU may differ substantially among patients, some of whom are admitted electively (e.g. after surgery) and stay for a short period, whereas others may spend weeks in the unit. ${ }^{[2,23]}$

To the best of our knowledge, there have been no studies in SA to explore parental satisfaction with the care given in a PICU. This study therefore aimed: to explore parental satisfaction with family-centred care domains in the PICU of the RCWMCH in Cape Town, SA; to explore parents' experiences of their child's stay in the PICU, and to 
compare our findings with those described by Latour et al. ${ }^{[15]}$ in the Netherlands.

\section{Methods \\ Study design}

A prospective descriptive survey study, using multiple methods, was conducted between November 2014 and February 2015. The University of Cape Town's Human Research Ethics Committee approved the study (ref. no. 814/2014) and written informed consent was obtained from all participants, in their language of choice. The vulnerability of the study participants at a time of intense emotional stress was acknowledged and social work support was available to all participants.

\section{Participants}

We included a convenience sample of 100 parents or legal guardians of medically stable children who had been admitted to the PICU at the RCWMCH for at least 48 hours and who were present and available during normal work hours. Excluded from the study were: parents or guardians of children who were discharged from the PICU within 48 hours or who died in the PICU; parents who were in a state of severe emotional distress (as this could impact on their ability to provide informed consent for the study), ${ }^{[24]}$ and parents of children enrolled in another clinical trial.

\section{Study site}

The RCWMCH is a public tertiary hospital and is linked to the University of Cape Town as a teaching hospital. It serves the entire Western Cape province, parts of the Eastern Cape and even other parts of Africa. At the time of the study, the 22-bed multidisciplinary PICU admitted approximately 1400 children per annum. Many children are from very poor socioeconomic backgrounds. The patient population is diverse, with both emergency and elective admissions (including following cardiac surgery). There is a hospital facility to lodge up to 80 parents from outside Cape Town. Parents receive accommodation and three meals per day, at ZAR 40 per day.

\section{The EMPATHIC-30 questionnaire}

The self-administered EMPATHIC-30 questionnaire was used as the research tool and was translated from English to isiXhosa and Afrikaans using forward-backward translation. The EMPATHIC-30 is a shortened version of the EMPATHIC-65 questionnaire, ${ }^{[25]}$ which was developed in the Netherlands and validated in a cohort study of 3354 parents of children admitted to eight Dutch PICUs. ${ }^{[15]}$ Crossvalidation among the different sites showed adjusted $R^{2}$ values for different domains to be between $85 \%$ and $95 \%$, highly correlated to the original, full version of the questionnaire $(r=0.92-0.97)$. Reliability of the different domains (expressed as Cronbach's $\alpha$ ) ranged from 0.73 to $0.93 .^{[15]}$

The EMPATHIC-30 comprises three sections: the first collects general information on the PICU patients and their parent/s, the second asks Likert-scale questions in five domains related to parental satisfaction with the quality of PICU care, and the third section comprises four open-ended, free-text questions in which parents are invited to share their PICU experiences. The questionnaire was fundamentally unchanged from the original; ${ }^{[15]}$ however, the item 'Cultural background' was removed from Section 1, as ethnicity was not considered relevant to the research question in the SA context.

Section 2 of the questionnaire consists of 30 items organised into five domains: information (5 items); care and cure (8 items); organisation (5 items); parental participation (6 items) and professional attitude of staff (6 items). Responses for each domain are given on a 6-point ordinal Likert scale ( $1=$ highly disagree; $6=$ highly agree), with an additional 'not applicable' option at each question. A score of $\leq 3$ was considered 'negative', whereas a score of $\geq 4$ was considered a 'positive' response. ${ }^{[15]}$ Average scores for each domain(total score/number of questions per domain) are presented.

In the four open-ended questions, participants were invited to 'tell us [their] story' of experiences 'during the admission period', 'during the actual PICU stay', 'regarding discharge from the PICU', and any other 'general experiences'. These questions were intentionally very broad, to allow participants to comment on or share a wide range of experiences.

\section{Other variables}

The following baseline characteristics of patients (the participants' children) were recorded from the medical folders: age; gender; diagnosis; length of stay prior to study recruitment; and severity of illness on admission (assessed using the Paediatric Index of Mortality (PIM2) score). ${ }^{[26]}$

\section{Procedure}

Eligible participants were identified by PICU consultants in conjunction with the social worker. Participants completed the questionnaire independently or with the assistance of the researcher if needed, in their language of choice. Open-ended answers written in isiXhosa or Afrikaans were translated into English by a language expert for qualitative analysis.

\section{Quantitative analysis}

Quantitative data analysis was conducted using descriptive statistics, calculated using means (and associated standard deviations) for normally distributed variables and medians (and associated interquartile ranges) for variables that were not normally distributed. The internal consistency of the subscales and total scale of the EMPATHIC questionnaire was calculated using Cronbach's $\alpha$. To compare mean subscale values of our study with those of Latour et al. ${ }^{[15]}$ we calculated Cohen's $d$ using the following formulae:

Cohen's $d=\left(\right.$ Mean $_{2}-$ Mean $\left._{1}\right) S D_{\text {pooled }}$

$S D_{\text {pooled }}=\sqrt{ }\left(\left(S D_{1}^{2}+S D_{2}^{2}\right) / 2\right)$, where $S D_{\text {pooled }}$ is the pooled standard deviation.

Measured as Cohen's $d$, an effect size of $<0.20$ was considered small, a value of 0.50 was seen as moderate, and a value of $\geq 0.80$ was large. ${ }^{[27]}$ If the questionnaire was administered before PICU discharge, two items about discharge were expected not to be answered. A $p$-value of $<0.05$ was considered statistically significant (two-tailed). Quantitative data were analysed using SPSS version 22.0, IMB Corp., USA.

\section{Qualitative analysis}

Answers to the four open-ended, free-text questions on parental experiences were analysed using thematic analysis, ${ }^{[28]}$ with the responses coded and themes developed.

Trustworthiness of the qualitative results was considered using the principles of: confirmability (i.e. results are based on actual participant responses and not arising from researcher bias); credibility (i.e. the truthfulness and accuracy of the study findings); transferability (i.e. how applicable the findings are in the prevailing social and cultural contexts), and dependability (i.e. sufficient description of the study to allow repeatability). ${ }^{[29]}$ 
Confirmability was ensured by having a student not involved in the care of children in the PICU collect the data, and therefore the participants would likely have been more comfortable to present their real thoughts and experiences without the concern that their responses would affect the care of their children (this was also explicitly stated in the informed consent form). Thematic analysis of all verbatim responses was checked by an independent qualitative researcher to ensure that both positive and negative themes emerging from the data were reported. An external researcher, who reviewed the research process and data analysis, served as inquiry auditor to ensure dependability. Credibility was ensured by inviting free responses, without judgement, from a sufficiently large and representative sample of parents in the PICU, without preselection of participants. The quantitative responses to the questionnaire also served to confirm the qualitative findings.

\section{Results}

A total of 239 children were admitted to the PICU over the study period and parents or legal guardians of 100 patients were included in the study (Fig. 1).

Of the 100 questionnaires, 77 were completed by the mother, 7 by the father, 6 by the mother and father together, and 10 by others (grandmother, aunt or legal guardian). The researcher (CM) assisted 69 participants

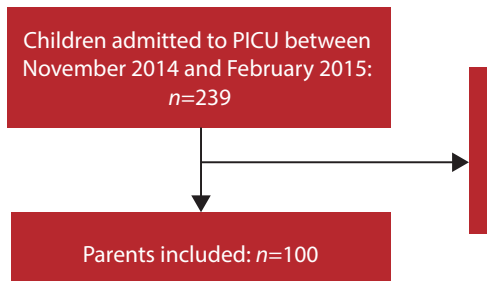

\section{Parents included: $n=100$}

Fig. 1. Flow chart of sample selection.

\begin{tabular}{ll} 
Table 1. Patient characteristics $(\mathbf{N = 1 0 0})$ & \\
\hline Variables & Percentage (\%) \\
\hline PICU length of stay (days), median (IQR) & $3(2-6)$ \\
Until interview $(N=99)$ & $5(3-10)$ \\
Total until discharge $(N=96)$ & $9.4(2.2-65.2)$ \\
Age (months), median (IQR) & \\
Age group & 14.0 \\
Newborns & 51.0 \\
1 month - 3 years & 35.0 \\
>3 years & \\
Gender & 54.0 \\
Male & 46.0 \\
Female & \\
Mechanical ventilation required & 88.0 \\
Yes & 12.0 \\
No & \\
Primary PICU diagnostic category & 27.0 \\
Cardiovascular & 19.0 \\
Respiratory & 18.0 \\
Shock and sepsis & 9.0 \\
Cardiothoracic surgery & 6.0 \\
Trauma & 6.0 \\
Other infection & 5.0 \\
Neurological & 4.0 \\
Gastrointestinal & 2.0 \\
Oncology & 2.0 \\
Transplantation & 2.0 \\
Neurosurgical & $7.4(3.4-17.6)$ \\
PIM2 score (\%), median (IQR) & \\
PICU = paediatric intensive care unit; IQR = interquartile range; PIM2 = Paediatric Index of Mortality. \\
&
\end{tabular}

in completing the questionnaire, while 31 participants completed the questionnaire by themselves. Almost three-quarters (74\%) of the questionnaires were completed before a patient's discharge from the PICU.

Table 1 presents characteristics of the participants' admitted children (patients). The majority of patients were admitted for emergency management of medical conditions, most commonly of cardiovascular (27\%) or respiratory nature $(19 \%)$, or shock or sepsis (18\%). Most patients (88\%) received mechanical ventilation (Table 1).

\section{Responses from Section 2 of the EMPATHIC-30 questionnaire}

The internal consistency of the five domains in this section of the questionnaire, expressed as Cronbach's $\alpha$, ranged between 0.25 (Parental participation) and 0.59 (Care and cure) (Table 2). This was lower than the range $(0.73-0.81)$ reported in the study by Latour et al. ${ }^{[15]}$ (Table 2).

Overall, the responses in Section 2 were overwhelmingly positive, with mean satisfaction scores for each domain (total domain score/number of questions in the domain) between 5.50 and 5.77 out of a maximum possible score of 6 (Table 2). In all the domains, the mean scores for the subdomains were higher in the current study than those reported by Latour et al. ${ }^{[15]}$ and associated with a moderate to large effect size (Cohen's $d=0.45$ - 0.86) (Table 2).

The lowest response values were found associated with one question in the 'Information' and two questions in the 'Parental participation' domains: 19 participants indicated that they were not adequately informed about the possible effects of medication; $16 \%$ responded negatively (score $\leq 3$ ) with regard to the frequency of the staff's enquiry about parents' experiences, and $13.1 \%$ responded negatively to the item probing the level of involvement they experienced in making decisions about their children's treatment or care.

\section{Responses from Section 3 of the EMPATHIC-30 questionnaire}

The majority (97.0\%) of participants completed at least one of the open-ended questions in this section. Parents repeated the same themes in the 'General experiences' question and the findings regarding this question are consequently not reported on separately. 
Table 2. Standardised mean scores, internal consistency and effect size of the satisfaction domains of the EMPATHIC-30 questionnaire compared with findings by Latour et al. ${ }^{[15]}$

\begin{tabular}{|c|c|c|c|c|c|c|c|}
\hline \multirow[b]{2}{*}{ Domain } & \multirow[b]{2}{*}{$N$} & \multirow[b]{2}{*}{$\begin{array}{l}\text { Number of } \\
\text { questions }\end{array}$} & \multicolumn{2}{|c|}{ Mean score (SD) } & \multirow[b]{2}{*}{$\begin{array}{l}\text { Effect size } \\
\text { (Cohen's } d \text { ) }\end{array}$} & \multicolumn{2}{|c|}{ Internal consistency (Cronbach $\alpha)$} \\
\hline & & & $\begin{array}{l}\text { Current study } \\
\text { (RCWMCH) }\end{array}$ & Latour et al. ${ }^{[15]}$ & & $\begin{array}{l}\text { Current study } \\
\text { (RCWMCH) }\end{array}$ & Latour et al..$^{[15]}$ \\
\hline Information & 96 & 5 & $5.50(0.71)$ & $5.15(0.85)$ & 0.45 & 0.49 & 0.76 \\
\hline \multirow[t]{2}{*}{ Care and cure } & $31^{*}$ & 8 & $5.74(0.42)$ & $5.21(0.76)$ & 0.86 & 0.54 & 0.81 \\
\hline & 97 & 6 & - & - & - & 0.59 & - \\
\hline Organisation & 100 & 4 & - & - & - & 0.52 & - \\
\hline Parental participation & 99 & 6 & $5.54(0.51)$ & $5.25(0.73)$ & 0.47 & 0.25 & 0.75 \\
\hline Professional attitude & 98 & 6 & $5.77(0.49)$ & $5.44(0.63)$ & 0.58 & 0.50 & 0.78 \\
\hline
\end{tabular}

Table 3. Selected verbatim responses related to the admission process

\begin{tabular}{|c|c|c|}
\hline Emerging theme & Participant & Response \\
\hline \multirow[t]{3}{*}{ Communication } & 75 & 'Doctors informed me immediately about the procedure that was going to be done.' \\
\hline & 12 & 'We can ask any questions and they are willing to answer.' \\
\hline & 36 & 'We were introduced to staff and well informed about our child's condition.' \\
\hline \multirow{3}{*}{$\begin{array}{l}\text { Support from doctors, nurses and social worker, } \\
\text { hospital staff }\end{array}$} & 15 & 'I do not feel alone because of the social worker.' \\
\hline & 24 & $\begin{array}{l}\text { 'I didn't feel lonely and too much pain, because when I came they comfort me and } \\
\text { took my baby nicely'. }\end{array}$ \\
\hline & 31 & 'I was welcomed and the receptionist was friendly'. \\
\hline
\end{tabular}

\section{Experiences of admission to the unit}

Two main themes emerged relating to the admission period, namely communication and support from healthcare professionals (doctors, nurses, social workers and other hospital staff).

Parents were generally positive about the communication between themselves and the PICU staff (Table 3). They appreciated: being informed about their child's condition, treatment and PICU procedures; having their questions answered; being introduced to the PICU team, and explanations about the PICU equipment or 'machines'. However, some parents did note a language barrier leading to discomfort, as not being able to speak the same language as the nurses made them feel the nurses were 'gossiping about [the] child or me' (participant 24). Some parents also commented on the equipment and their alarms being 'very scary' and 'overwhelming' (participant 68 ). The welcoming and supportive attitude from doctors and nurses was experienced positively, both during the admission process and their PICU stay (Table 3).

\section{Stay at the unit}

The four main themes identified with regard to the PICU stay were: environmental factors; proximity to the child; availability of medical staff, their working together and showing respect, and social support among mothers (Table 4).

Parents were initially scared and ill at ease when they arrived at the PICU, and experienced the alarms and equipment as stressful and noisy. During their children's stay in the PICU, they became more accustomed to the new environment and started feeling more at ease (Table 4). Most parents mentioned the cleanliness of the PICU and the associated parents' facilities as a positive aspect. Light was mentioned as a notable factor in both the waiting room, which parents did not like to be dark, and the main PICU, where the filtered sunlight was experienced as 'calming. Some parents perceived there to be insufficient space around the beds to accommodate parents, the machines and also the nurses. To improve the comfort of the waiting room, access to a working television, eating and drinking facilities and comfortable chairs were suggested.

Privacy was noted as an aspect for improvement in the main PICU. Some parents did not like to see or hear other patients, or were concerned about infections because children with different conditions were treated in the same room. Some parents indicated that they would prefer a main PICU divided into separate units to improve infection control. However, other parents appreciated the setup of the main PICU and even liked to share a room, to prevent it from being 'boring and lonely' (participant 10).

Being close to their child during their PICU stay was important to parents (Table 4). Some were satisfied with being able to sit next to their child's bed all day and appreciated the open visiting hours. Others perceived the parents' facility as being too far away from the PICU (participant 78) or complained about only one parent being allowed to stay with their child at night (participant 27).

Parents were positive about the availability of the medical staff and how they worked together (Table 4). Knowing that there was always a nurse checking on their child made parents feel safe. Disrespectful treatment from a nurse made the PICU experience less positive for some parents, while respectful treatment made the experience positive for others.

The social support mothers received from other mothers emerged as a prominent theme in that it was a source of strength and hope (Table 4). The parent facility was perceived to enhance this social support system among parents, as people were able to eat, sit, wait and sleep together.

\section{Discharge}

This question was not completed in many cases, as the majority of children had not yet been discharged from the PICU at the time 
Table 4. Selected verbatim responses related to participants' experiences of their child's stay in the paediatric intensive care unit

\begin{tabular}{ll}
\hline Emerging theme & 80 \\
\hline Environmental factors (alarms, & \\
machines, privacy, space, light) & \\
Being close to the child & \\
& \\
& \\
&
\end{tabular}

$\begin{array}{ll}\text { Participant } & \text { Response } \\ 80 & \text { 'I don't like th }\end{array}$

night.

10 'I was in shock to hear all the alarms. Now it's normal to come in the main ICU.'

12 'ICU is too small. It's very traumatising. It's very bad space for myself. When you come to see your child, you see also other children suffering.'

'In as far as ICU is con
want to with my child?'

64 'I am allowed to touch, sing and pray for my baby. I am given enough space to bond with her.'

17 'Sometimes as a parent you live far from the hospital and you are unemployed, then it becomes

78 'The only problem as mother is that they should make room near the ICU for mothers to sleep in, cause the mothers room are too far from the kids that and I didn't sleep for 3 days cause I didn't wanted to be far from my kid.

\begin{tabular}{|c|c|c|}
\hline \multirow{4}{*}{$\begin{array}{l}\text { Medical staff availability; working } \\
\text { together; showing respect }\end{array}$} & 86 & 'I'm feel better just because the doctors and the nursing is near the baby, which means you is safe.' \\
\hline & 61 & 'I liked that everyone worked together and understand each other.' \\
\hline & 13 & 'Some of the night staff could improve on their attitudes to the patients and parents.' \\
\hline & 16 & 'The doctors and nurses they are very kind respectful to us and our babies.' \\
\hline \multirow[t]{3}{*}{ Social support among mothers } & 65 & $\begin{array}{l}\text { 'While staying here I wasn't as stressed out, because I met and got to know some other mothers } \\
\text { who are going through the same thing.' }\end{array}$ \\
\hline & 87 & $\begin{array}{l}\text { 'During admission ICU I was heartbroken but hopeful because other mothers who have been } \\
\text { there before me, gave me strength.' }\end{array}$ \\
\hline & 95 & 'The stay was wonderful because you make friends, who also build your strength and hope.' \\
\hline
\end{tabular}

$\mathrm{ICU}=$ intensive care unit.

Table 5. Selected verbatim responses related to participants' experiences of discharge

\begin{tabular}{ll}
\hline Participant & Response \\
\hline 17 & 'The child is discharged when he/she is much better and taken to the ward. By that time you as a parent, you are also satisfied.' \\
7 & 'It didn't take long. They explained to me what was gonna happen.' \\
51 & 'They all said bye to us. It was nice, really. It was nice. Everything went quick quick.' \\
35 & 'We have been well informed.'
\end{tabular}

of their parents completing the questionnaire. Participants whose children had been discharged, however, provided positive feedback about the efficiency of discharge and the information received in preparation for discharge (Table 5).

\section{Discussion}

In the past few decades, paediatric intensive care has expanded considerably owing to technological advances, improved medical knowledge and the involvement of multidisciplinary teams. ${ }^{[1]}$ Current efforts to explore parental satisfaction and implement family-centred care further improve the quality of care. ${ }^{[4]}$ To our knowledge, the use of a previously validated tool (the EMPATHIC-30 questionnaire ${ }^{[15]}$ ) is the first report of measuring parental satisfaction in a PICU in SA.

Overall, parents and guardians reported positive experiences in all domains measured by the questionnaire. However, potential for improvement was identified with regard to parental participation and information, which are important aspects of family-centred care. Inviting active involvement of parents and guardians in decision-making about the care and treatment of their child and properly informing them about the indications, effects and possible side-effects of medications were highlighted as areas for the improvement of practice in the PICU. It is notable that family-centred care has been defined in different ways, and with different emphases according to different contexts. ${ }^{[9,16,30]}$ Irlam and Bruce ${ }^{[16]}$ suggested that family-centred care in developed countries involves care led by parents in dialogue with medical staff, whereas family-centred care in SA is recommended to focus on parents' participation in care.

The definition of parental participation is wide-ranging, and may include physical, psychological and social care. One proposed definition for parental participation refers to 'parents' active involvement in specific levels of care based on negotiation, agreement, and mutual open interactive relationships [with healthcare professionals]... through exchange of information and increase in parents' level of awareness and skills. ${ }^{[31]}$ In the PICU context, different models of parental participation have all been associated with reduced parental anxiety and higher satisfaction levels; ${ }^{[2]}$ however, there is as yet insufficient evidence of the impact of parental participation on child outcomes. ${ }^{[30,32]}$ The feedback from our study highlights that parental participation in care is also important to parents of critically ill children managed in a PICU in the SA context.

Communication and support from healthcare professionals were highlighted in the open-ended questions as being important to parents or guardians. Receiving understandable information about the PICU and their child's condition and treatment was valued, although a language barrier was identified as causing some respondents to feel excluded or alienated. This may explain the relatively low scores seen in the 'Knowledge' domain in Section 2 of the questionnaire. Some respondents also expressed the need for more information about the 
equipment and their functions, as these and their associated alarms aroused stress and anxiety, particularly around the time of PICU admission. It is, however, not clear how much information parents are able to assimilate and understand at the time of intense emotional stress when their child is admitted to the PICU. ${ }^{[24]}$ It is therefore suggested that explanation and discussion should continue throughout a patient's PICU stay to ensure their parents' or guardians' full understanding and so optimise parental engagement.

Language barriers, as mentioned by some participants, may adversely impact on effective healthcare and patient outcomes. ${ }^{[33,34]} \mathrm{SA}$ is a multilingual society and communication barriers between healthcare professionals and patients or their families have been identified as important contributors to emotional distress and dissatisfaction with health services. ${ }^{[35,36]}$ From the same centre as this study, Levin et al. ${ }^{[37]}$ reported that language and cultural barriers were noted by parents as a major barrier to healthcare, more so than either structural or socioeconomic challenges.

Effective communication between families and healthcare providers has been shown to be essential for establishing a relationship of mutual trust, to minimise conflict, reduce family stress levels and improve parental satisfaction with care, and is therefore a fundamental component of patient- and family-centred care. ${ }^{[38,39]}$ Communication may occur in formal, structured settings (e.g. scheduled family meetings and ward rounds), but there are also countless unstructured interactions between healthcare providers and patients' parents or guardians, which should also be acknowledged. ${ }^{[38]}$ In the SA context, where healthcare providers and patients may speak a range of different languages, other aspects of communication, which may not directly involve the parent but which may affect them, should also be considered. For example, discussing a parent's child in a foreign language may lead to distrust, which is not conducive to a healing environment. Familycentred healthcare requires clear communication between healthcare providers and the patients or their carers. ${ }^{[33]}$ It is therefore suggested that healthcare professionals pay attention to both the verbal and non-verbal cues used around patients and their families. Healthcare providers should consider what is being said, their chosen language and paralinguistic features such as tone of voice, facial expressions, gestures and other body language cues; interpretation (or misinterpretation) is impacted on not just by what is said, but also by how people sound and behave while speaking. ${ }^{[40]}$

The right to participate in all aspects of life in the language of choice and for one's language to be respected are principles enshrined in the SA constitution. ${ }^{[41]}$ However, owing to disparate educational levels, different socioeconomic and cultural backgrounds and different culture-specific models for explaining disease, there may be frequent miscommunication even when patients (or their families) and healthcare professionals share a common language. ${ }^{[42]}$ 'Cultural competence' is a strategy aimed at addressing disparities in healthcare as a consequence of racial, ethnic and language difference, and is of particular importance given the turbulent sociopolitical history of SA. ${ }^{[34]}$ Developing cultural competencies among healthcare professionals may therefore be an important consideration in optimising family-centred care and improving health outcomes.

Macdonald et al. ${ }^{[7]}$ suggested that family-centred care should include aspects of architectural elements and facility design. Some parents in our study expressed preference for a large communal PICU, as they felt they would feel lonely or bored if they had a single, private room for their child. However, others would have preferred a single room or a PICU divided into separate units to prevent the risk of hospitalacquired infections and to avoid seeing and hearing other patients and their families. Soft, filtered natural light, feeling welcome at admission and the presence of friends and family made parents feel at ease. These findings correspond with results from a US study by Bazuin and Cardon, ${ }^{[43]}$ in which they discuss the contribution of architecture, interior design and behaviour to healing intensive care environments. Private rooms may improve the ability of PICU staff to adhere to the principles of confidentiality and privacy, as adjacent families in mixed units are usually able to hear conversations and ward round discussions of other patients. ${ }^{[7]}$ Bazuin and Cardon ${ }^{[43]}$ reported reduced family and patient stress when children were managed in private PICU rooms and a reduction in hospital-acquired infection transmission rates. There is, however, a tension between staffing levels and PICU layout, as more staff would be required to serve multiple separate rooms, which might not be feasible in resource-constrained settings. Notably, though, this design element was considered in developing a new PICU at RCWMCH, where several private rooms are now available for children with specific healthcare needs or infection control requirements.

Being close to the child was important to parents, similar to what has been reported in other studies. ${ }^{[4]}$ This was facilitated by the unit's open visitation policy, which has previously been shown to be associated with improved patient and family satisfaction, improved trust in the healthcare provided, and improved understanding about the patient's condition. ${ }^{[4]}$ Some parents did, however, indicate that they did not like that only one parent was allowed to stay with the child at night, and this rule could be reconsidered. A striking feature was the importance of social support among mothers of critically ill children, which was facilitated by the availability and use of parent accommodation on the hospital premises. Previous research has identified that parents need a place to sleep in the hospital in order to be close to their critically ill child ${ }^{[45]}$ and the importance of providing food and amenities to support family presence in the PICU. ${ }^{[46]}$

\section{Study limitations}

The internal consistency between the domains in Section 2 spanned a considerable range $(\alpha=0.25-0.59)$ in our study. These values were lower than those reported by Latour et al., ${ }^{[15]}$ which could be explained by the substantially smaller sample size in our study, but may also reflect differences in experiences and contexts between the two study sites. The wide range of socioeconomic, educational, language and cultural backgrounds of parents of patients admitted to this study site could explain the low internal consistency in the parental participation domain, compared with findings reported by Latour et al. ${ }^{[15]}$ A low internal consistency value may further suggest that additional relevant items should be added to the questionnaire for use in the SA context. This requires further research.

The mean scores recorded in the various subdomains in this study were higher than those reported by Latour et al. ${ }^{[15]}$ which suggests higher satisfaction levels; however, the scores may have been influenced by the fairly small sample size in our study (100 v. 3454 participants) and the majority of questionnaires (74\%) being administered before PICU discharge as opposed to some time after discharge, as in the study by Latour et al. ${ }^{[15]}$ The different methodology was chosen for pragmatic reasons, as it is known that loss to follow-up in children is common after hospital discharge in our context. It is possible that questioning parents about their PICU experiences before discharge might have introduced bias, as parents may have been concerned about sharing negative experiences while still dependent on the facility for their child's healthcare; however, there is similarly also the potential for recall bias when remembering experiences in the PICU after discharge. 
Including only parents of children who were recovering from their critical illness (all were discharged from the PICU alive) is also a limitation of this study, as we were not able to gauge the experiences of parents whose children died in the PICU. Exploring this aspect is recommended for future studies. Our study was also conducted in a single site, and therefore results cannot be generalised to other PICUs in SA or beyond.

Despite the EMPATHIC-30 questionnaire including questions about participation, parents were not specifically questioned about how and to what extent they were directly or indirectly involved in their child's care as a partner in care or in the role of care provider. ${ }^{[32]}$ Further research is recommended to explore the nature and extent of, and preferences for, parental participation in PICU care in SA.

\section{Recommendations}

Further studies with larger sample sizes and across multiple sites are required to develop a locally validated and reliable questionnaire on parents' satisfaction with and experiences of PICU care for use in the culturally diverse SA context. Including parents whose children did not survive to PICU discharge would be important in future studies to reduce bias; however, this would require sensitivity and ethical oversight to prevent creating additional psychological anguish for already bereaved parents.

\section{Conclusion}

Although parents were generally highly satisfied with the quality of care received in this PICU, our results suggest that family involvement and information provision, as fundamental aspects of family-centred care in the PICU, could be improved. The importance of environmental factors, social support among mothers of critically ill children, and the value of close proximity to their child while in the PICU, emerged as important themes from this study.

\section{Acknowledgements. Monique van Dijk and Roelie Wösten-Van Asperen are thanked for their external oversight of this student project.}

Author contributions. As the student investigator of this study, CM developed the protocol, collected and analysed the data and wrote the initial draft of the paper. ACA and BMM provided guidance and supervision throughout the research process.

Funding. None.

Conflicts of interest. None.

1. Epstein D, Brill JE. A history of pediatric critical care medicine. Pediatr Res 2005;58(5):987-996. https://doi.org/10.1203/01.pdr.0000182822.16263.3d

2. Curtis K, Foster K, Mitchell R, Van C. Models of care delivery for families of critically ill children: An integrative review of international literature. J Pediatr Nurs 2016;31(3):330-341. https://doi. org/10.1016/j.pedn.2015.11.009

3. Committee On Hospital Care and Institute for Patient and Family-Centered Care. Patientand family-centered care and the pediatrician's role. Pediatrics 2012;129(2):394-404. https://doi. org/10.1542/peds.2011-3084

4. Meert KL, Clark J, Eggly S. Family-centered care in the pediatric intensive care unit. Pediatr Clin North Am 2013;60(3):761-772. https://doi.org/10.1016/j.pcl.2013.02.011

5. Committee on Hospital Care. Family-centered care and the pediatrician's role. Pediatrics 2003;112(3):691696. https://doi.org/10.1542/peds.112.3.691

6. Shields L, Pratt J, Hunter J. Family centred care: A review of qualitative studies. J Clin Nurs 2006;15(10):1317-1323. https://doi.org/10.1111/j.1365-2702.2006.01433.x

7. Macdonald ME, Liben S, Carnevale FA, Cohen SR. An office or a bedroom? Challenges for familycentered care in the pediatric intensive care unit. J Child Health Care 2012;16(3):237-249. https://doi. org/10.1177/1367493511430678

8. Hutchfield K. Family-centred care: A concept analysis. J Adv Nurs 1999;29(5):1178-1187. https://doi. org/10.1046/j.1365-2648.1999.00987.x

9. Latour JM, Hazelzet JA, Van der Heijden AJ. Parent satisfaction in pediatric intensive care: A critical appraisal of the literature. Pediatr Crit Care Med 2005;6(5):578-584. https://doi.org/10.1097/01. pcc.0000164637.88469.74

10. Latour JM, Van Goudoever JB, Hazelzet JA. Parent satisfaction in the pediatric ICU. Pediatr Clin North Am 2008;55(3):779-790. https://doi.org/10.1016/.pcl.2008.02.013

11. Co JP, Ferris TG, Marino BL, Homer CJ, Perrin JM. Are hospital characteristics associated with parental views of pediatric inpatient care quality? Pediatrics 2003;111(2):308-314. https://doi org/10.1542/peds.111.2.308

12. Majdalani MN, Doumit MA, Rahi AC. The lived experience of parents of children admitted to the pediatric intensive care unit in Lebanon. Int J Nurs Stud 2014;51(2):217-225. https://doi org/10.1016/j.ijnurstu.2013.06.00
13. Grandjean C, Latour JM, Cotting J, Fazan MC, Leteurtre S, Ramelet AS. Measurement of parent satisfaction in the paediatric intensive care unit - translation, cultural adaptation and psychometric equivalence for the French-speaking version of the EMPATHIC-65 questionnaire. Intensive Crit Care Nurs 2017;38:40-45. https://doi.org/10.1016/ji.iccn.2016.09.001

14. Latour JM, Hazelzet JA, Duivenvoorden HJ, Van Goudoever JB. Construction of a parent satisfaction instrument: Perceptions of pediatric intensive care nurses and physicians. J Crit Care 2009;24(2):255266. https://doi.org/10.1016/j.jcrc.2008.06.002

15. Latour JM, Duivenvoorden HJ, Tibboel D, Hazelzet JA, EMPATHIC Study Group. The shortened EMpowerment of PArents in THe Intensive Care 30 questionnaire adequately measured parent satisfaction in pediatric intensive care units. J Clin Epidemiol 2013;66(9):1045-1050. https://doi. org/10.1016/j.jclinepi.2013.02.010

16. Irlam LK, Bruce JC. Family-centred care in paediatric and neonatal nursing - a literature review. Curationis 2002;25(3):28-34. https://doi.org/10.4102/curationis.v25i3.781

17. Pilar Orive FJ, Basabe Lozano J, Lopez Zuniga A, Lopez Fernandez YM, Escudero Argaluza J, Latour JM. [Spanish translation and validation of the EMPATHIC-30 questionnaire to measure parental satisfaction in intensive care units]. An Pediatr (Barc) 2018;89(1):50-57. https://doi.org/10.1016/j. anpede.2017.08.006

18. Witulska K, Migdal M, Sulich E, Piotrowski A, Latour J. The Empathic-30 questionnaire is reliable and valid for Polish pediatric intensive care units. Eur J Pediatr 2016;175(11):1575. http://hdl.handle. net/10026.1/10868

19. Wolfler A, Giannini A, Finistrella M, et al. EMpowerment of PArents in THe Intensive Car Questionnaire: Translation and validation in Italian PICUs. Pediatr Crit Care Med 2017;18(2):e77e85. https://doi.org/10.1097/pcc.0000000000001031

20. Mikkelsen G, Rasmussen B, Larsson K. Abstract P-355: Translation of the Danish version of the EMPATHIC-30 questionnaire. Pediatr Crit Care Med 2018;19(6S):155-156. https://doi. org/10.1097/01.pcc.0000537812.77313.44

21. Motsoaledi A. Progress and changes in the South African health sector. Lancet 2012;380(9858):19691970. https://doi.org/10.1016/s0140-6736(12)61997-7

22. Vermeulen JM, Van Dijk M, Van der Starre C, Wösten-Van Asperen RM, Argent AC. Patient safety in South Africa: PICU adverse event registration. Pediatr Crit Care Med 2014;15(5):464-470. https:// doi.org/10.1097/pcc.0000000000000114

23. Nupen T, Argent AC, Morrow BM. Characteristics and outcome of long-stay patients in a paediatric intensive care unit in Cape Town, South Africa. S Afr Med J 2017;107(1):70-75. https://doi, org/10.7196/samj.2017.v107i1.11279

24. Morrow BM, Argent AC, Kling S. Informed consent in paediatric critical care research - a South African perspective. BMC Med Ethics 2015;16:62. https://doi.org/10.1186/s12910-015-0052-6

25. Latour JM, Van Goudoever JB, Duivenvoorden HJ, et al. Construction and psychometric testing of the EMPATHIC questionnaire measuring parent satisfaction in the pediatric intensive care unit. Intensive Care Med 2011;37(2):310-318. https://doi.org/10.1007/s00134-010-2042-y

26. Slater A, Shann F, Pearson G, Paediatric Index of Mortality (PIM) Study Group. PIM2: A revised version of the Paediatric Index of Mortality. Intensive Care Med 2003;29(2):278-285. https://doi. org/10.1007/s00134-002-1601-2

27. Cohen J. Statistical power analysis for the behavioral sciences. 2nd ed. Hillsdale: Lawrence Erlbaum, 1988.

28. Braun V, Clarke, V. Using thematic analysis in psychology. Qual Res Psychol 2006;3(2):77-101. https://doi.org/10.1191/1478088706qp063oa

29. Shenton AK. Strategies for ensuring trustworthiness in qualitative research projects. Educ Inform 2004;22:53-75. https://doi.org/10.3233/EFI-2004-22201

30. Shields L, Zhou H, Pratt J, Taylor M, Hunter J, Pascoe E. Family-centred care for hospitalised children aged 0-12 years. Cochrane Database Syst Rev 2012;10:CD004811. https://doi.org/10.1002/14651858 cd004811.pub3

31. Vasli P, Salsali M. Parents' participation in taking care of hospitalized children: A concept analysis with hybrid model. Iran J Nurs Midwifery Res 2014;19(2):139-144.

32. Latour JM, Van Goudoever JB, Duivenvoorden HJ, et al. Perceptions of parents on satisfaction with care in the pediatric intensive care unit: The EMPATHIC study. Intensive Care Med 2009;35(6):1082 1089. https://doi.org/10.1007/s00134-009-1491-7

33. Goenka PK. Lost in translation: Impact of language barriers on children's healthcare. Curr Opin Pediatr 2016;28(5):659-666. https://doi.org/10.1097/mop.0000000000000404

34. Matthews M, Van Wyk J. Towards a culturally competent health professional: A South African case study. BMC Med Educ 2018;18(1):112. https://doi.org/10.1186/s12909-018-1187-1

35. Hussey N. The language barrier: The overlooked challenge to equitable health care. S Afr Health Rev 2012:189-195.

36. Van den Berg VL. Still lost in translation: Language barriers in South African health care remain S Afr Fam Pract 2016;58(6):229-231. https://doi.org/10.1080/20786190.2016.1223795

37. Levin M. Language as a barrier to care for Xhosa-speaking patients at a South African paediatric teaching hospital. S Afr Med J 2006;96(10):1076-1079.

38. Zurca AD, Corriveau CO. Family communication in the PICU: Less than ideal no matter how you say it. Crit Care Med 2014;42(6):1569-1570. https://doi.org/10.1097/ccm.0000000000000255

39. Zurca AD, Fisher KR, Flor RJ, et al. Communication with limited English-proficient families in the PICU. Hosp Pediatr 2017;7(1):9-15. https://doi.org/10.1542/hpeds.2016-0071

40. Blanch-Hartigan D, Ruben MA, Hall JA, Schmid Mast M. Measuring nonverbal behavior in clinical interactions: A pragmatic guide. Patient Educ Couns 2018;(in press). https://doi.org/10.1016/j. pec.2018.08.013

41. Constitution of the Republic of South Africa, Act 108 of 1996. 17th Amendment, 2012. http://www wipo.int/edocs/lexdocs/laws/en/za/za107en.pdf

42. Levin M. Language and allergy education: Review article. Curr Allergy Clin Im 2014;27(4):290-291.

43. Bazuin D, Cardon K. Creating healing intensive care unit environments: Physical and psychological considerations in designing critical care areas. Crit Care Nurs Q 2011;34(4):259-267. https://doi. org/10.1097/cnq.0b013e31822b8f76

44. Davidson JE, Aslakson RA, Long AC, et al. Guidelines for family-centered care in the neonatal, pediatric, and adult ICU. Crit Care Med 2017;45(1):103-128. https://doi.org/10.1097/ $\mathrm{ccm} .0000000000002169$

45. Meert KL, Templin TN, Michelson KN, et al. The Bereaved Parent Needs Assessment: A new instrument to assess the needs of parents whose children died in the pediatric intensive care unit. Crit Care Med 2012;40(11):3050-3057. https://doi.org/10.3410/f.718022454.793479228

46. Eggly S, Meert KL. Parental inclusion in pediatric intensive care rounds: How does it fit with patientand family-centered care? Pediatr Crit Care Med 2011;12(6):684-685. https://doi.org/10.1097/ pcc.0b013e318202f602

Accepted 24 October 2018. 